material, make for competitive cartographic work. The accuracy of the map declines as information accumulates or over-simplification ensues in keeping with customer demands or business concerns.

Andrews contends that "maps become as correct as paper and ink will allow, or for that matter, as the users desire." He tells of the scale issue in which 'improvement lies henceforth in selectiveness rather than completeness.' The simple problem of placing all that needs to be mapped with the constraint of a single sheet of paper made for some difficult decisions.

Within the time-span of two and a half centuries, Andrew's cites the key-map concept as integral to the appreciation of Irish map history. As time progresses, the key-map concept the evolutionary flow (of information) may divide instead of converging, and one powerful family may be challenged by another of the same generation. The solution is then to treat both contenders as key maps.' This solution definitely has a limit, that the unique distinction of key map not be widely applied and cartographic history become redundant. The mapping of Ireland now is at the behest of the computer. Geographical information systems have made the change of scale and point coverage a matter of mathematical adjustment. Map history of Ireland is still in the making, as is the mapping of this green and beautiful land.

In conclusion, J. H. Andrews has compiled and written a comprehensive account of the mapping history of Ireland. It is also a story of colonization and conquest of a country by an imperial power. This is a world-wide tale in history. The story has more than one ending. There could be other characters. The issues of the history of cartography are relevant to other places and times. Andrews has shown the relevance of cartography to history and place and the people who make the maps. Those who inhabit this land may have less interest in the story. The conquered not only have less voice, but perhaps less interest in the conquered land, as they struggle for their daily needs. Remembering it was for militarism and tourism, following the Irish famine that maps reached a zenith of popularity. The cartographic history here is seemingly as complete as it could be, short of a wonderful discovery that would fill in some early gaps. It probably would be Andrews himself who would be the scholarly discoverer of such missing links in the map history of Ireland. I wish him well, that he never completely closes the book on his research in this most interesting area.

\section{Counties USA 1997: A Directory of United States Counties. Kay} Gill and Darren L. Smith, eds. Detroit: Omnigraphics, Inc., 1997. 573 pp., Index, Maps. $\$ 85.00$ hardcover (ISBN 0-7808-0094-X).

Reviewed by Scott R. McEathron American Geographical Society Collection, Golda Meir Library Univ. of Wisconsin-Milwaukee Milwaukee, WI 53211

This basic reference book provides limited descriptive statistical data for each county in the United States. The counties are arranged alphabetically by chapters for each state, making the book very easy to use. Each state chapter is proceeded by a Bureau of the Census base map showing the boundaries and names for each of the counties in that state. Basic contact information for state officials (telephone and fax numbers, and Internet addresses) are then provided. Contact information is also given for each county and includes the county seat mailing address, telephone and fax numbers, and Internet address when available.
The descriptive statistical data provided for each county includes both 1990 and 1995 population, population density (1995), and land and water area in square miles. Brief descriptions of the county's location and name origin are also given.

The book has limited utility since all of this information it contains can be found in other sources. The 1990 population, population density, land and water area in square miles, and the brief descriptions of the county's location and name origin is the same as what can be found in American Places Dictionary (Omnigraphics, Inc., 1994). The 1996 County and City Extra: Annual Metro, City and County Data Book (Bernan Press, 1996) is a much more comprehensive source for statistical data. Carroll's Municipal/County Directory: 1996 Annual (Carroll Publishing, 1996) has much more comprehensive contact information at the county level. Similarly, Carroll's State Directory: 1997 Library Edition (Carroll Publishing, 1997) provides more comprehensive contact information at the state level.

The most disturbing thing about Counties USA 1997 is the large number of errors evident in the land in square miles data. A possible printing or data entry problem caused all counties with land or water areas of four or more digits to be incorrect. For example, the land area for Bayfield County, Wisconsin is listed as 1 square mile! In reality it is 1,476 square miles. This problem results in an unacceptable number of errors of fact thoughout the book. In western states such as Wyoming, where all counties have land areas greater than 1,000 square miles, the number listed for the area in square miles is always wrong. Because all of the information in Counties USA 1997 is found in other sources and the many obvious errors, it is difficult to recommend its purchase to any individual or institution. 